\title{
Right lower lobectomy eight years after left pneumonectomy for a second primary lung cancer
}

\author{
Yunpeng Liu', Peipeng Cui ${ }^{2}$, Zhiguang Yang ${ }^{1}$, Peng Zhang ${ }^{1}$, Rui Guo ${ }^{3}$ and Guoguang Shao ${ }^{\text {** }}$
}

\begin{abstract}
Lobectomy for second primary lung cancer in a patient with previous pneumonectomy is seldom done because most such patients either have inadequate pulmonary reserve or metastatic disease at other sites. This is different than when this type of surgery is done for benign disease where the lobe to be resected is already non functional. We report a case where successful right lower lobectomy for a second primary lung cancer was carried out in a 53 year old man who had had a left pneumonectomy eight years before. We conclude that, although this type of approach can be worthwhile, surgeons must be cautious and selective before doing so.
\end{abstract}

Keywords: Second primary lung cancer, Pneumonectomy, Lobectomy

\section{Background}

Contralateral lobectomy after pneumonectomy is rarely done for lung cancer [1-9] because most such patients have inadequate cardiopulmonary reserve or metastatic disease at distant sites. This is different than what is seen in benign lung disease where the lobe to be removed is already non functional and cardiopulmonary adjustments have occurred over the previous several years [10-12]. We are presenting a case in which a successful right lower lobectomy (RLL) for second primary lung cancer was performed eight years after left pneumonectomy.

\section{Case presentation}

A 53 year old man with previous left pneumonectomy done eight years before for stage $2 \mathrm{~B}$ squamous cell carcinoma was reassessed for increased cough and hemoptysis. The patient was otherwise well, had stopped smoking after his pneumonectomy, was not complaining of dyspnea, and had no significant other comorbidities. Chest CT showed a $4 \mathrm{~cm}$ mass in the RLL (Figure 1) without abnormal bronchopulmonary or mediastinal lymph nodes. At bronchoscopy, an endobronbchial tumor was seen in the medial basal segmental bronchus of the right

\footnotetext{
* Correspondence: guoguangshao@sohu.com

'Department of Thoracic Surgery, First Hospital of Jilin University, Changchun, Jilin Province 130021, PR of China

Full list of author information is available at the end of the article
}

lower lobe and biopsies confirmed the diagnosis of squamous carcinoma. Brain CT, isotopic bone scan, and abdominal ultrasonography were negative for distant metastases.

Preoperative pulmonary function studies showed moderate obstructive changes (Table 1) but what appeared to be adequate pulmonary reserve. Forced expiratory volume in the first second $\left(\mathrm{FEV}_{1}\right)$ and carbon monoxide diffusing capacity (DLCO) were $43.6 \%(1,44 \mathrm{~L})$ and $71.7 \%$ $(20,19 \mathrm{ml} / \mathrm{min} / \mathrm{mmHg})$ of predicted values, respectivery. Cardiac ultrasonography showed that pulmonary artery pressure was normal at $22 \mathrm{~mm} \mathrm{Hg}$ and the ejection fraction of the left ventricle was also normal. Based on this evaluation, we thought that the patient could tolerate a right lower lobectomy although our primary objective was to try to do a sublobar segmental resection.

At operation, done through a standard posterolateral thoracotomy, it became obvious that a segmentectomy would not be technically possible and a right lower lobectomy with mediastinal lymphadenectomy was carried out. The resected tumor was pathologically staged $\mathrm{T}_{2} \mathrm{~N}_{2}$ (pTNM, stage 3A) because micrometastases were found in one subcarinal (station 7) node on final pathological examination but the resection was felt to be complete (RO resection).

The patient had a normal postoperative course although he required oxygen supplementation for the first 


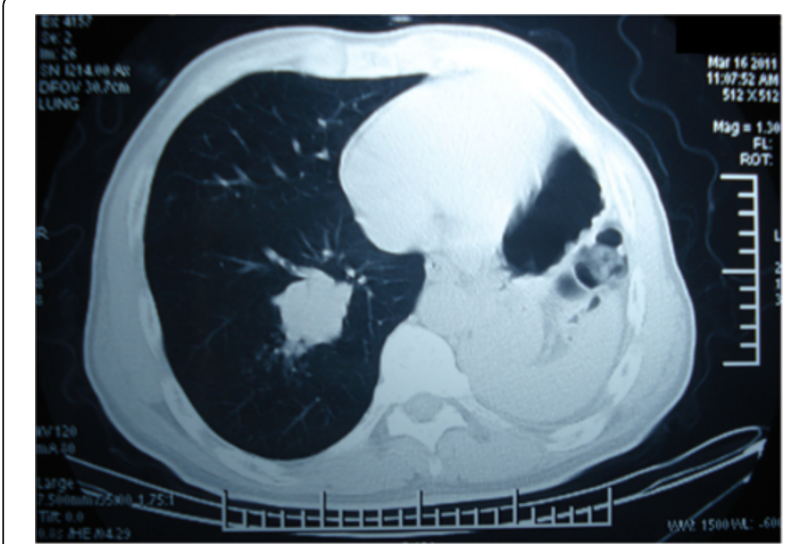

Figure 1 Preoperative chest CT showing a $4 \mathrm{~cm}$ mass in the right lower lobe. There is favorable hyperinflation of the right lung and normal postpneumonectomy status.

two weeks following the surgery. A standard chest radiograph (Figure 2) done when the patient was discharged from the hospital on postoperative day \# 25 and a CT scan (Figure 3) done ten months after surgery show that the residual right upper and middle lobe are well expanded with minimal postoperative changes. Interestingly, pulmonary function studies done on the $45^{\text {th }}$ postoperative day (Table 1) show that $\mathrm{FEV}_{1}$ values are identical to those before the lobectomy.

\section{Discussion}

Since pulmonary resection offers the best opportunity for long-term disease free survival in lung cancer patients, it is accepted that these patients should be offered a second operation should they develop a second primary after previous lobectomy. Such a decision is, however, more controversial, in patients with previous pneumonectomy expected to require lobectomy for complete resection of that second primary. Most previously reported cases are in the form of case reports $(2,3,5,8,9)$ and in the four largest series ever published $(1,4,6,7)$, only two out of a total of 65 patients underwent a lobectomy while the remaining 63 had wedges or segmentectomies. This reluctance to do a lobectomy after previous pneumonectomy in the context of lung cancer is because patients are at high risk of operative mortality due to respiratory

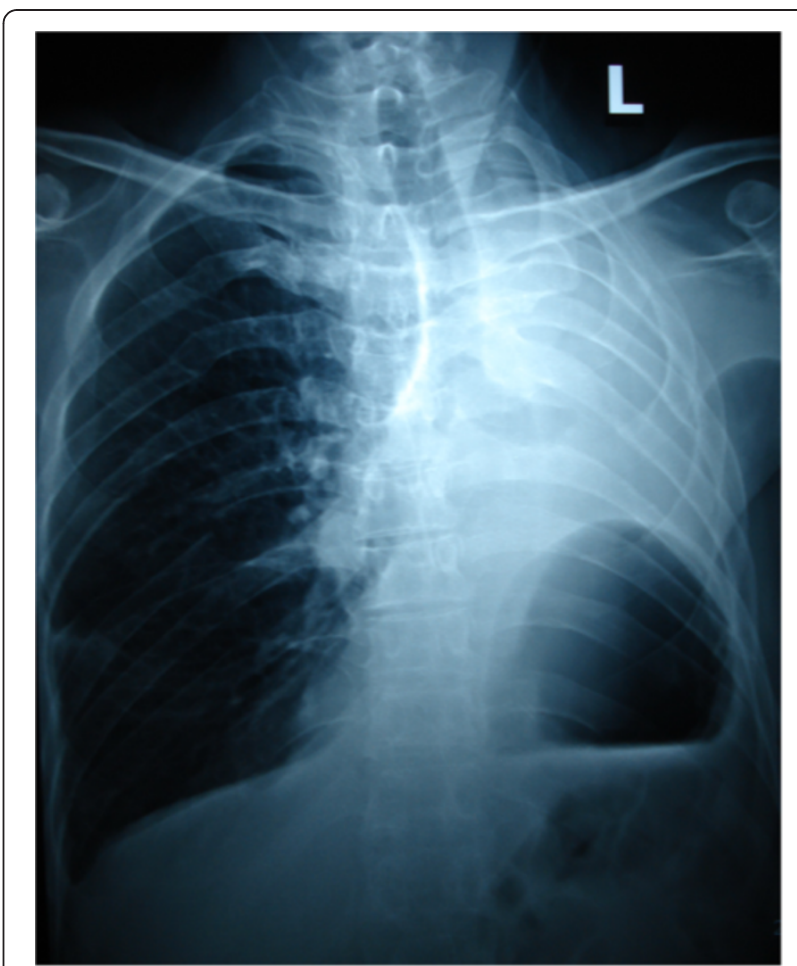

Figure 2 Standard radiograph done 25 days after surgery showing good expansion of the right upper and middle lobes and minimal postoperative inflammatory changes.

failure or pulmonary hypertension. This is different than what is seen in patients with benign diseases such as bronchiectasis or destroyed lungs which most of the time have been the result of repeated respiratory infections experienced in childhood [11]. In such cases, the lobe to be removed is nonfunctional and the cardiorespiratory system has had time to adjust to this situation over several years. One such reported patient lived an active life for more than three years with the RLL as his only lung tissue [10].

The most important issue in lung cancer patients expected to have subsequent lobectomy after previous pneumonectomy is how to select them for operation and how to predict which patients have enough cardiopulmonary reserve not only to survive the operation but also to have a good quality of life afterwards. Unfortunately, there is no easy formula to solve this dilemma

Table 1 Pre and postoperative spirometric values

\begin{tabular}{|c|c|c|c|c|}
\hline & \multicolumn{2}{|c|}{ Preoperative } & \multicolumn{2}{|c|}{$\begin{array}{l}\text { Postoperative } \\
\text { (45 days) }\end{array}$} \\
\hline & Observed & $\%$ Predicted & Observed & $\%$ Predicted \\
\hline FEV1 (L) & 1.44 & 43.6 & 1.40 & 42.2 \\
\hline $\mathrm{FVC}(\mathrm{L})$ & 2.16 & 52.8 & 1.45 & 35.3 \\
\hline FEV1/FVC (\%) & 66.7 & - & 96.5 & - \\
\hline DLCO (Ml/min/mmHg) & 20.19 & 71.7 & & \\
\hline
\end{tabular}




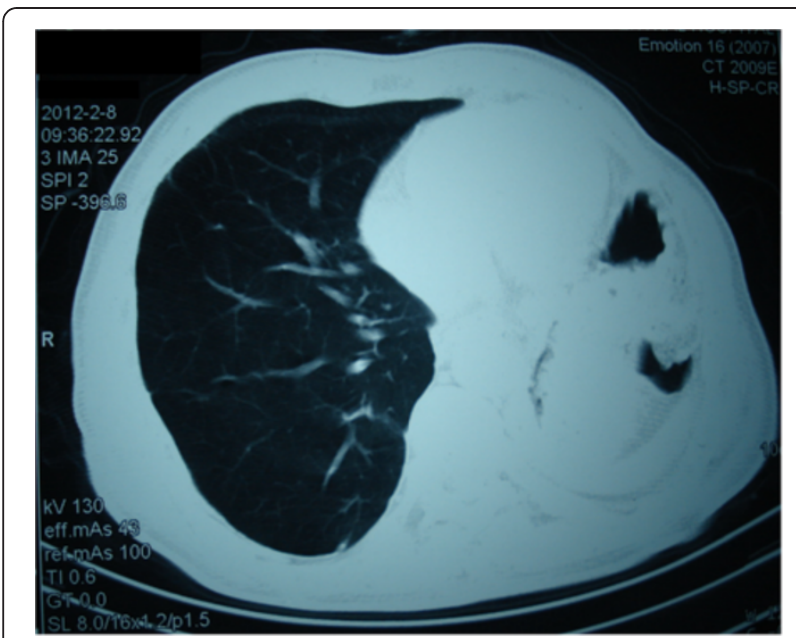

Figure 3 Chest CT done ten months after operation and showing good expansion of the residual lobes.

and, although this type of surgery may occasionally be worthwhile like it was in our case, one has to be very cautious before making such a decision. Obviously, clinical history and spirometric assessment of pulmonary function are important and can be predictive of good outcome even if there are no magic numbers for $\mathrm{FEV}_{1}$, FVC, or DLCO that will accurately predict postoperative course and eventual quality of life. In our case, preoperative $\mathrm{FEV}_{1}$ was $1,44 \mathrm{~L}$ (43.6\% of predicted) and, surprisingly, it remained identical at 45 days postoperatively. One can also do treadmill exercise-testing with measurement of maximal oxygen consumption $\left(\mathrm{VO}_{2} \mathrm{max}\right)$ and of arterial blood gases both at rest and during exercise. This was not done in our patient because he was in top physical condition having done manual work for all of his life.

Perhaps the most important preoperative assessment in that of cardiac function trying to predict if the patient will develop pulmonary hypertension during the postoperative period. Although direct measurements of pulmonary artery pressure can be done through heart catheterization, we think that a similar assessment can be achieved with cardiac ultrasonography. In our case, right ventricle and pulmonary artery pressures were normal as assessed by ultrasonography meaning that right heart function was normal and that the patient's pulmonary arterial system could probably tolerate a lobectomy if required by intraoperative findings.

\section{Conclusion}

This case indicates that lobectomy after previous pneumonectomy can be done in selected patients with adequate cardiopulmonary reserve. Since there are no preoperative values that are absolutely predictive of good outcome, surgeons must be very cautious before recommending operation.

\section{Consent}

Written informed consent was obtained from the patient for publication of this case report and any accompanying images. Copy of the written consent is available for review.

\section{Competing interest \\ There is no potential competing interest with this article.}

\section{Authors' contributions}

YL: main author wrote the paper. PC: performed the surgery and participated in the management. ZY: revised the manuscript. PZ and RG: participated in the design of the case report and performed the search in the literature. GS: performed the surgery reviewed the manuscript, and is the corresponding author. All authors read and approved the final manuscript.

\section{Acknowledgement}

Guoguang Shao. Paper resubmitted for publication in the Journal of Cardiothoracic Surgery case report.

\section{Author details}

${ }^{1}$ Department of Thoracic Surgery, First Hospital of Jilin University, Changchun, Jilin Province 130021, PR of China. ${ }^{2}$ Second Hospital of Jilin University, Changchun, Jilin 130041, China. ${ }^{3}$ Department of Thoracic Surgery, Siping Central Hospital, Siping, Jilin 136000, China.

Received: 28 November 2012 Accepted: 11 March 2013 Published: 15 March 2013

\section{References}

1. Kittle CF, Faber LP, Jensik RJ, Warren WH: Pulmonary resection in patients after pneumonectomy. Ann Thorac Surg 1985, 40:294-299.

2. Barker JA, Yahr WZ, Krieger BP: Right upper lobectomy twenty years after left pneumonectomy. Preoperative Evaluation and Follow-Up. Chest 1990, 97:248-250.

3. Terzi A, Furlan G, Falezza G, Gorla A: Left pneumonectomy for a second primary tumor after right upper lobectomy for superior Sulcus tumor. Thorac Cardiovasc Surg 1996, 44:155-157.

4. Spaggiari L, Grunenwald D, Girard P, Baldeyrou P, Filaire M, Dennewald G, Saint-Maurice O, Tric L: Cancer resection on the residual lung after pneumonectomy for bronchogenic carcinoma. Ann Thor Surg 1996, 62:1598-1602.

5. Spaggiari L, Grunenwald D, Girard P, Baldeyrou P: Completion right lower lobectomy for recurrence after left pneumonectomy for metastases. case report. Eur J Cardiothraocic Surg 1997, 12:798-800.

6. Donnington JS, Miller DL, Rowland CC, Deschamps C, Allen MS, Trastek VF, Pairolero P: Subsequent pulmonary resection for bronchogenic carcinoma after pneumonectomy. Ann Thorac Surg 2002, 74:154-159.

7. Terzi A, Londardini A, Scanagatta P, Pergher S, Bonadiman C, Calabrò F: Lung resection for bronchogenic carcinoma after pneumonectomy. A Safe and Worthwhile Procedure. Eur J Cardiothoracic Surg 2004, 25:456-459.

8. Quiroga J, Prim JMG, Moldes M, Ledo R: Middle lobectomy after pneumonectomy. Case study. Asian Cardiovasc Thorac Ann 2009, 17:300-301.

9. Baysungur V, Okur E, Tuncer L, Halezeroglu S: Sequential right upper sleeve lobectomy and left pneumonectomy for bilateral synchronous lung cancer. Eur J Cardiothoracic Surg 2009, 35:743-744.

10. Kürklü EU, LeRoux BT: Left pneumonectomy and middle lobectomy for bronchiectasis. Thorax 1973, 28:535-536.

11. Judd DR, Vincent KS, Kinsella PW, Gardner M: Long-term survival with the right lower lobe as the only lung tissue. Ann Thorac Surg 1985, 40:623-624.

12. Terzi A, Furia S, Biondani G, Calabro F: Sequential left pneumonectomy and right upper lobectomy for hemoptysis in post-tuberculosis destroyed lung and aspergilloma. Miverva Chir 2008, 63:175-179.

\section{doi:10.1186/1749-8090-8-46}

Cite this article as: Liu et al:: Right lower lobectomy eight years after left pneumonectomy for a second primary lung cancer. Journal of Cardiothoracic Surgery 2013 8:46. 